\title{
PROPRIEDADES DA SUPERFÍCIE E VARIÁVEIS CLIMÁTICAS PARA MODELAGEM DE ZONAS CLIMÁTICAS LOCAIS EM PRESIDENTE PRUDENTE
}

\author{
CARDOSO, Renata dos Santos - renata.cardoso@unesp.br \\ Universidade Estadual Paulista - Presidente Prudente / UNESP
}

AMORIM, Margarete Cristiane de Costa Trindade - margarete.amorim@unesp.br Universidade Estadual Paulista - Presidente Prudente / UNESP

Submetido em: $31 / 10 / 2020$

Aceito para publicação em: 22/03/2021

Publicado em: 30/06/2021

DOI: http://dx.doi.org/10.5380/abclima.v28i0.77636

\begin{abstract}
RESUMO: Investigar as interações entre superfície e atmosfera, compreender os mecanismos associados que contribuem para o aquecimento urbano, assim como a descrição e modelagem adequadas, são medidas necessárias para minimizar efeitos indesejados no clima das cidades. Esse estudo apresenta a caracterização de zonas climáticas locais (LCZs) em Presidente Prudente-SP, com a síntese das etapas de construção de uma base de dados da superfície e climáticos para modelagem no ENVImet. Os resultados demonstram que os contrastes térmicos entre LCZs com diferentes geometrias e coberturas da terra $\left(\Delta T_{\mathrm{LCZ}}\right.$ 3-B $)$ podem exceder $6^{\circ} \mathrm{C}$ em condições sinóticas estáveis. Esse diagnóstico é fundamental para avaliar os fatores que influenciam o campo térmico e simular cenários com estratégias de redução da temperatura urbana.
\end{abstract}

PALAVRAS-CHAVE: Clima urbano, ilhas de calor, LCZ.

\section{SURFACE PROPERTIES AND CLIMATE VARIABLES FOR MODELING LOCAL CLIMATE ZONES IN PRESIDENTE PRUDENTE}

\begin{abstract}
Investigating the interactions between surface and atmosphere and understanding the associated mechanisms that increase the urban heat, as well as their proper description and modeling, are necessary measures to minimize undesirable effects on urban climate. In this study, local climate zones (LCZs) in Presidente Prudente-SP are described and the steps taken to organize a database of surface properties and climate variables for modeling using ENVI-met are summarized. Results show that the thermal contrasts between LCZs with different geometries and land covers ( $\Delta T_{\text {LCZ 3-B }}$ ) can exceed $6^{\circ} \mathrm{C}$ in stable atmospheric conditions. This diagnosis is essential to assess the properties that influence thermal climate and simulate scenarios for devising strategies to reduce urban temperatures.
\end{abstract}

KEYWORDS: Urban climate, heat islands, LCZ.

\section{PROPIEDADES DE LA SUPERFICIE Y VARIABLES CLIMÁTICAS PARA MODELAR ZONAS CLIMÁTICAS LOCALES EN PRESIDENTE PRUDENTE}

RESUMEN: Investigar las interacciones entre la superficie y la atmósfera, comprender los mecanismos asociados que aumentan el calor urbano, así como también su adecuada descripción y modelización, son medidas necesarias para minimizar los efectos indeseables sobre el clima urbano. Este estudio describe las zonas climáticas locales (LCZs) en Presidente Prudente-SP y resume los pasos tomados para organizar una base de datos de propiedades de la superficie y variables climáticas para la simulación con ENVI-met. Los resultados muestran que los contrastes térmicos entre LCZs con diferentes geometrías y coberturas de la superficie $(\Delta T$ LCZ 3-B $)$ pueden superar los $6^{\circ} \mathrm{C}$ en condiciones atmosféricas estables. Este diagnóstico es fundamental para evaluar las propiedades que 
influyen en el clima térmico y simular escenarios con estrategias para reducir las temperaturas urbanas.

PALABRAS CLAVE: Clima urbano, islas de calor, LCZ.

\section{INTRODUÇÃO}

As transformações decorrentes do processo de urbanização proporcionam mudanças radicais nas superfícies naturais e nas propriedades atmosféricas da cidade. Isso envolve a transformação das características aerodinâmicas, radiativas, térmicas e de umidade, o que consequentemente perturba os balanços energéticos e hidrológicos naturais (OKE et al., 2017).

A densidade de materiais construtivos faz do sistema urbano um grande armazenador de calor e impermeabiliza a superfície. A geometria das edificações forma superfícies rugosas, com a possibilidade de interceptação da radiação e a estagnação do ar, e o calor e a água liberados como "resíduos" das atividades humanas suplementam as fontes naturais desses elementos no sistema urbano, provocando um desequilíbrio (OKE, 1987).

Essa substituição das superfícies naturais por estruturas e materiais urbanos de alta capacidade térmica e baixa permeabilidade é uma das principais causas das ilhas de calor na camada do dossel. O ar nessa camada é mais aquecido em comparação com o da área rural próxima, e as diferenças de temperatura entre o urbano e o rural $\left(\Delta T_{u-r}\right)$ são tomadas para indicar a intensidade ou magnitude da ilha de calor (STEWART; OKE, 2012).

Embora $\Delta T$ u-r seja amplamente utilizado como medida da alteração do clima nas cidades, não representa bem a diversidade de locais de medição "urbanos" e "rurais" que caracterizam as ilhas de calor na literatura. Além do problema em representar uma variedade de locais por uma taxonomia ambígua e inclusiva, o uso da tradicional classificação "urbano-rural" limita o avanço nos métodos e na comunicação da literatura sobre ilhas de calor (STEWART, 2007; 2011).

Para ultrapassar essa limitação, Stewart (2011) propôs o sistema de classificação da paisagem denominado Local Climate Zone (LCZ), ou zona climática local, através do qual a paisagem é dividida de acordo com as propriedades da morfologia da superfície e cobertura da terra. Nessa proposta, a intensidade das ilhas de calor é definida pela diferença de temperatura entre LCZs $\left(\Delta T_{\mathrm{LCZ} X-Y}\right)$, abordagem que favorece as análises por ser baseada em uma estrutura que destaca a forma construída e a superfície comum dos locais de campo comparados (STEWART; OKE, 2012).

Outra aplicação das LCZs consiste na construção de bancos de dados sobre morfologia e cobertura da superfície, assim como os efeitos térmicos associados. O sistema pode fornecer dados de entrada para modelos numéricos que incorporam parâmetros do dossel urbano em suas formulações, possibilitando a simulação de diferentes condições e variáveis climáticas.

Nesse contexto, com o objetivo de aplicar essa funcionalidade, este estudo apresenta a caracterização de LCZs em Presidente Prudente-SP, 
sintetizando as etapas de construção de uma base de dados da superfície e climáticos para simulações com o modelo microclimático ENVI-met ${ }^{1}$.

\section{MATERIAIS E MÉTODOS}

\section{1 ÁREA DE ESTUDO}

Presidente Prudente, situada no extremo oeste do estado de São Paulo (Fig. 1), latitude: $22^{\circ} 7^{\prime} 39^{\prime \prime}$ Sul e longitude: $51^{\circ} 23^{\prime} 8^{\prime \prime}$ Oeste, possui área urbana de aproximadamente $60 \mathrm{~km}^{2}$ e população estimada de 228.743 habitantes (Instituto Brasileiro de Geografia e Estatística - IBGE, 2019).

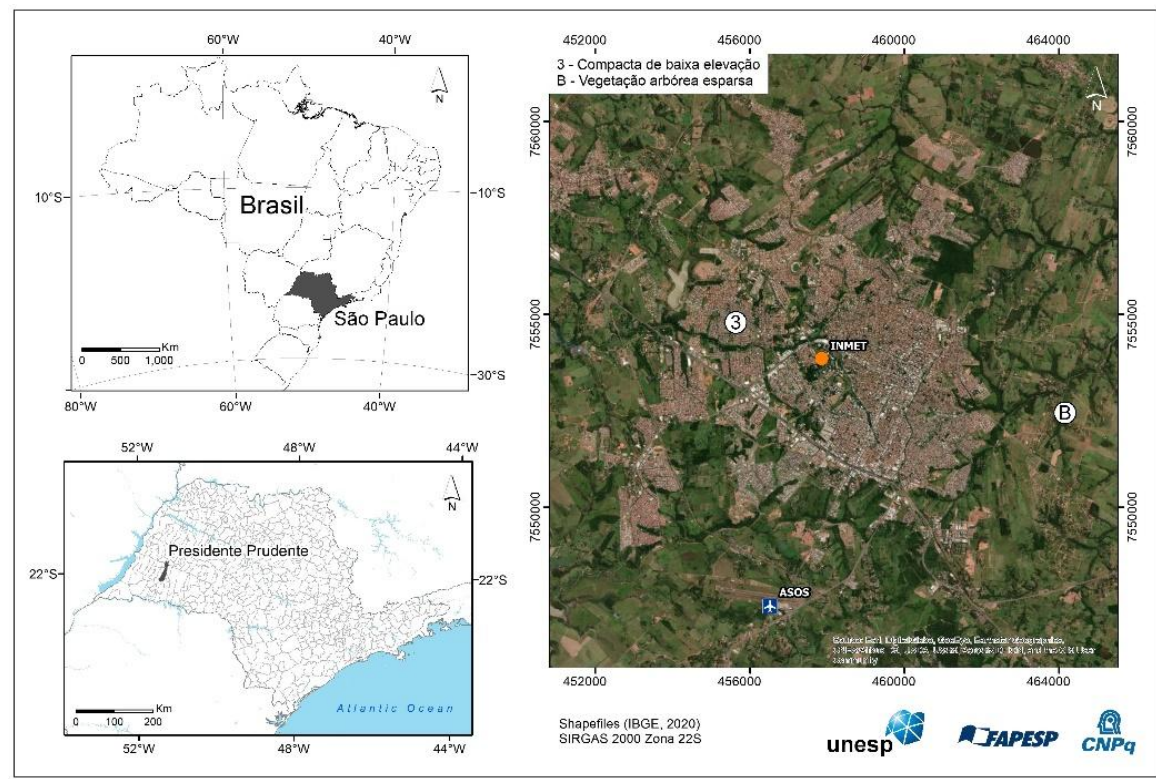

Figura 1 - Localização da área de estudo

A cidade encontra-se sob um regime de clima tropical com estação seca de inverno (Aw), segundo a classificação de Köppen (DUBREUIL et al., 2019). Ao longo da série histórica de 1969 a 2019 (Fig. 2) houve o registro de temperaturas médias máximas do ar acima de $30^{\circ} \mathrm{C}$ ao longo dos meses, e valores máximos diários próximos de $40^{\circ} \mathrm{C}$ durante a primavera e o verão, período tipicamente mais chuvoso.

As temperaturas médias atingiram cerca de $26^{\circ} \mathrm{C}$ nos meses de verão e oscilaram entre $20^{\circ} \mathrm{C}$ e $23^{\circ} \mathrm{C}$ durante o outono e o inverno. As temperaturas mínimas diárias apresentaram valores próximos ou abaixo de zero entre maio e agosto, período caracterizado por baixos totais pluviométricos.

\footnotetext{
${ }^{1}$ ENVI-met ${ }^{\circledR}$ é marca registrada na Alemanha sob o n. 30473896.
} 


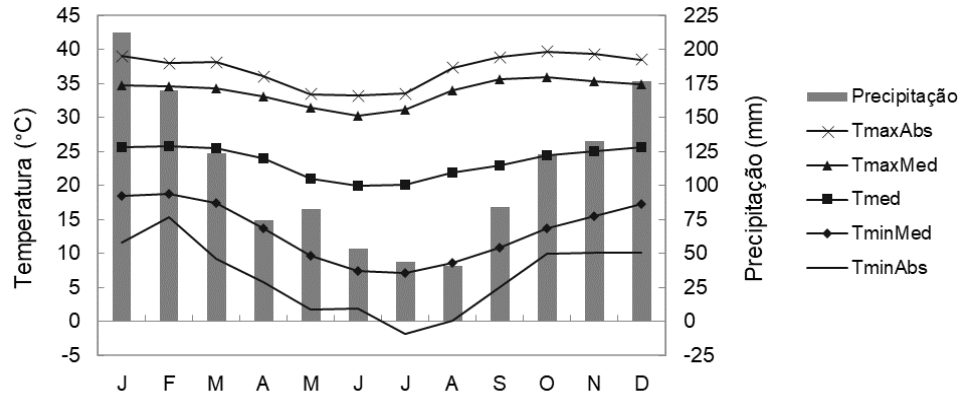

Figura 2 - Climograma de Presidente Prudente-SP (1969-2019). Fonte: Instituto Nacional de Meteorologia (INMET)

No que se refere ao relevo local, as formas predominantes são os morrotes alongados, espigões e as colinas médias (NUNES, 2011). As cotas altimétricas na malha urbana variam, aproximadamente, entre $380 \mathrm{~m}$ nas planícies de córregos e fundos de vale no setor oeste, e $495 \mathrm{~m}$ ao longo do topo do espigão na zona leste da cidade.

A área urbana apresenta uma mistura complexa de paisagens heterogêneas em espaços reduzidos e vegetação dispersa. O núcleo urbano central, caracterizado pelo grande fluxo de pessoas e veículos, corresponde a áreas densamente construídas com poucas ou nenhuma árvore. Por outro lado, os bairros residenciais que se estendem a oeste do centro da cidade apresentam edifícios mais espaçados e cobertura vegetal.

Em direção à periferia oeste, lotes densamente construídos com pouco ou nenhum espaço livre para a vegetação caracterizam a maioria dos bairros residenciais. Esse padrão espacial compacto também ocorre na porção norte, onde as residências apresentam características construtivas que aumentam a temperatura ambiente (por exemplo, paredes finas e telhados tipicamente de fibrocimento) (CARDOSO; AMORIM, 2018).

Verifica-se também a implantação e consolidação de grandes aglomerados habitacionais, onde o distanciamento da malha urbana consolidada pode limitar o acesso às infraestruturas, serviços e equipamentos públicos. Têm-se ainda a predominância de lotes pequenos e impermeabilizados, e um padrão construtivo aquém do adequado às características climáticas da cidade para a garantia do conforto térmico aos habitantes (CARDOSO; AMORIM, 2015).

O entorno próximo à malha urbana é composto por propriedades rurais, vegetação arbórea esparsa, superfície coberta por pastagem e poucas construções. Essa configuração da paisagem tipicamente rural tem relação com as diferentes fases da atividade agropecuária em Presidente Prudente (HESPANHOL, 2017), além das transformações decorrentes da expansão territorial urbana e dos empreendimentos imobiliários.

\subsection{BASE DE DADOS DA SUPERFÍCIE E VARIÁVEIS CLIMÁTICAS}

A primeira etapa desse estudo consistiu na definição das áreas de interesse, seguida da construção da base de dados da superfície e das variáveis climáticas necessárias para a caracterização das zonas climáticas locais em Presidente Prudente. 


\subsubsection{SELEÇÃO DAS LCZS}

A seleção dos locais de estudo teve como referência o aporte metodológico de Stewart e Oke (2012), no qual definem um conjunto de diretrizes para a utilização do sistema de classificação de LCZ nas investigações sobre as ilhas de calor.

Nesse sistema, a paisagem é a classe universal de observação das ilhas de calor e é dividida de acordo com as propriedades da superfície (morfologia e cobertura da terra) que influenciam o campo térmico na camada do dossel. A estrutura das LCZs tem como base dados observacionais e de modelagem numérica e sua representação compreende 17 classes: 10 relacionadas aos tipos de construções e 7 referentes aos tipos de cobertura da terra (STEWART; OKE, 2012; STEWART, 2011).

De forma geral, os autores recomendam a execução de três etapas ao classificar as áreas de estudo em LCZs:

1) obter dados para quantificar as propriedades da superfície (geometria das construções, cobertura da terra, relevo, fluxo de tráfego) por meio de pesquisas de campo ou fontes secundárias (fotografias aéreas, imagens de satélite, etc.);

2) definir a área de influência para a medição de temperatura, ou seja, a área da superfície na qual a temperatura se origina e é transportada até o sensor através fluxo de vento;

3) selecionar uma LCZ que melhor corresponda com o local de estudo, levando em consideração as propriedades da superfície. Caso não seja possível encontrar uma correspondência adequada, deve-se reconhecer esse fato e destacar as principais diferenças entre o local e a LCZ equivalente mais próxima.

Devido à disponibilidade de dados climatológicos de sensores instalados em diferentes pontos da cidade, no período de junho a dezembro de 2015 (AMORIM, 2017, 2020), a seleção das áreas de estudo ocorreu de forma que o entorno dos sensores instalados (em um raio de $200 \mathrm{~m}$ ) fosse relativamente homogêneo em relação à forma construída e cobertura da terra.

A princípio, com base na interpretação visual dos diferentes tipos de construções e de cobertura da terra representativos das paisagens típicas da cidade, decidiu-se trabalhar com as seguintes áreas: LCZ 3 - compacta de baixa elevação (bairro residencial popular densamente construído) e LCZ B vegetação arbórea esparsa (Fig. 3).

\section{LCZ 3 - Compacta de baixa elevação}

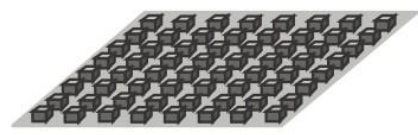

Mistura densa de edifícios entre 1 e 3 andares. Poucas ou nenhuma árvore. Cobertura da terra pavimentada. Materiais de construção: pedra, tijolo, telha e concreto.

\section{LCZ B - Vegetação arbórea esparsa}

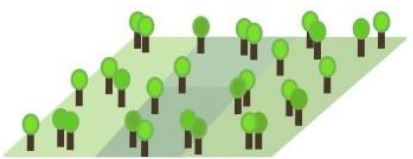

Paisagem levemente arborizada com árvores decíduas e/ou perenes. Cobertura da terra permeável (plantas baixas). Floresta natural, cultivo de árvores ou parque urbano.

Figura 3 - Ilustração das zonas climáticas locais (LCZs). Fonte: Imagens reproduzidas a partir de Stewart e Oke (2012) 


\subsubsection{PROPRIEDADES DA SUPERFÍCIE}

Para obter as propriedades da superfície dos locais selecionados, utilizouse a técnica de vizinho mais próximo (Nearest Neighbor - NN) baseada em objetos para classificar imagens de satélite de alta resolução espacial no eCognition $^{\mathrm{TM} 2}$ (CARDOSO et al., 2018).

A partir dos mapas de cobertura da terra e dos principais materiais construtivos, calculou-se o percentual da superfície edificada, impermeável e permeável nas áreas delimitadas, para comparar com os valores padrões de cada categoria definidos por Stewart e Oke (2012).

Posteriormente, foram realizados levantamentos para o cálculo da razão do aspecto $H / W$ (Height/Width) (OKE, 1988) (Fig. 4), parâmetro escolhido para caracterizar a geometria do cânion urbano em Presidente Prudente.

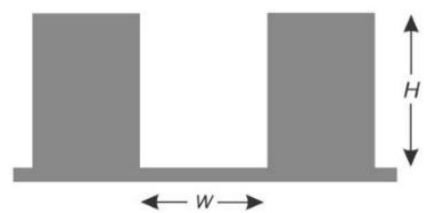

Figura 4 - Razão do aspecto do cânion urbano $H / W$

A altura média das construções $(H)$ foi estimada a partir de levantamentos referentes ao número de pavimentos de cada edifício na LCZ urbana. Com o auxílio de uma planta baixa das edificações impressa em papel, a contagem foi realizada in situ, incluindo os pavimentos térreos e sobrelojas, e a quantidade foi anotada em cada lote (Fig. 5).

\footnotetext{
${ }^{2}$ Copyright(C) Trimble Inc. Trimble eCognition Software.
} 


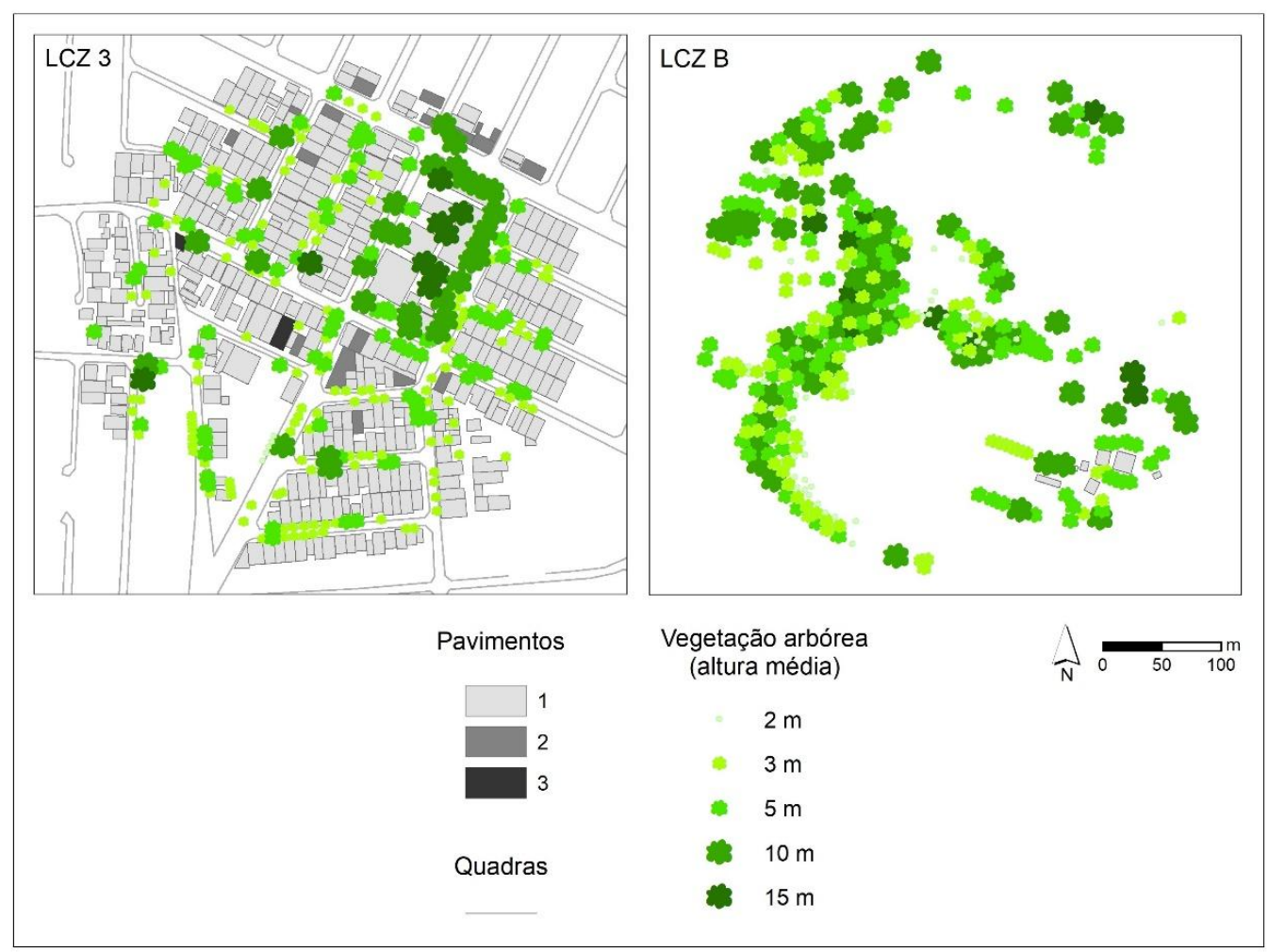

Figura 5 - Planta baixa dos edifícios e vegetação arbórea nas LCZs

Em seguida, os dados foram importados para o ArcMap $^{3}$ e cadastrados na tabela de atributos dos respectivos arquivos shp. Para o cálculo da altura média, adotou-se a medida de $3 \mathrm{~m}$ para cada pavimento padrão e $5 \mathrm{~m}$ para os pavimentos térreos com o pé-direito alto (NEUFERT, 2013; PRESIDENTE PRUDENTE, 2018; SILVA et al., 2018).

Para medir a largura das vias $(W)$ na LCZ 3, utilizou-se o aplicativo Google Earth Pro ${ }^{4}$ para obter as distâncias entre os edifícios separados pelas ruas e calçadas. Tendo em vista que a largura das ruas não é igual mesmo no interior de uma LCZ específica, optou-se por medir todas as distâncias na área delimitada (400 m de diâmetro) e calcular a largura média.

$\mathrm{Na}$ LCZ B, H correspondeu à altura média das árvores, enquanto $\mathrm{W}$ foi definido a partir do espaçamento médio entre as árvores.

Após estimar as razões $H / W$ médias nas LCZs, as propriedades das superfícies foram organizadas em fichas técnicas (STEWART, 2011; 2018; STEWART; OKE, 2012), com a descrição das principais características relacionadas à forma construída, cobertura da terra, fluxo de tráfego, função e localização.

\footnotetext{
${ }^{3}$ Copyright $\odot$ Esri. ArcGIS $®$ and ArcMap ${ }^{\mathrm{TM}}$ software.

${ }^{4}$ GOOGLE. Google Earth. Version 7.3.2.5776. 2019. Presidente Prudente-SP. Disponível em: https://www.google.com/earth/. Acesso em: fev. 2019.
} 


\subsubsection{DADOS METEOROLÓGICOS}

Com o intuito de selecionar episódios representativos das estações de verão e inverno, foram consideradas as condições sinóticas dos meses de junho e dezembro de 2015. Esse critério deve-se ao fato de as características atmosféricas exercerem grande controle nas diferenças térmicas intraurbanas e rurais, sendo que em situações ideais de calmaria ou ventos fracos e ausência de nuvens, a intensidade das ilhas de calor noturnas é maximizada.

Portanto, foram organizados os dados de direção e velocidade do vento, precipitação na área urbana (Estação: Presidente Prudente-A707, Código OMM: 86863, Instituto Nacional de Meteorologia - INMET), precipitação na área rural (Davis Vantage Pro2), nebulosidade (The Automated Surface Observing Systems - ASOS) e sistemas atmosféricos atuantes (AMORIM, 2017, 2020) (Tabelas 1 e 2).

Tabela 1 - Dados meteorológicos de junho de 2015 em Presidente Prudente

\begin{tabular}{ccccccc}
\hline Dia & $\begin{array}{c}\text { Velocidade média } \\
\text { do vento }\left(\mathrm{m} \mathrm{s}^{-1}\right) \\
\text { a }\end{array}$ & $\begin{array}{c}\text { Direção } \\
\text { predominante } \\
\text { do vento }\end{array}$ & $\begin{array}{c}\text { Precipitação } \\
\text { área urbana } \\
(\mathrm{mm})^{\mathrm{a}}\end{array}$ & $\begin{array}{c}\text { Precipitação } \\
\text { área rural } \\
(\mathrm{mm})^{\mathrm{b}}\end{array}$ & $\begin{array}{c}\text { Cobertura } \\
\text { de nuvens } \\
\text { (oktas) }\end{array}$ & $\begin{array}{c}\text { Sistemas } \\
\text { atmosféricos } \\
\mathrm{d}\end{array}$ \\
\hline 1 & 0,5 & $\mathrm{E}$ & 5,4 & - & 6 & $\mathrm{FPA}$ \\
2 & 1,3 & $\mathrm{E}$ & 0,4 & 1,01 & 7 & $\mathrm{FPA}$ \\
3 & 0,9 & $\mathrm{E}$ & - & 0,5 & 8 & $\mathrm{mPa}$ \\
4 & 1,3 & $\mathrm{SE}$ & - & 0,25 & 2 & $\mathrm{mPa}$ \\
5 & 1,2 & $\mathrm{E}$ & - & 0,25 & 4 & $\mathrm{mPa}$ \\
6 & 1,1 & $\mathrm{E}$ & - & - & 4 & $\mathrm{mTa}$ \\
7 & 0,7 & $\mathrm{E}$ & - & - & 2 & $\mathrm{mTa}$ \\
8 & 0,6 & $\mathrm{E}$ & - & - & 4 & $\mathrm{mTa}$ \\
9 & 0,6 & $\mathrm{E}$ & - & - & 2 & $\mathrm{mTa}$ \\
10 & 0,7 & $\mathrm{E}$ & - & - & 2 & $\mathrm{mTa}$ \\
\hline 11 & 1,2 & $\mathrm{NE}$ & - & - & 2 & $\mathrm{mTa}$ \\
\hline 12 & 0,6 & $\mathrm{NW}$ & - & - & 4 & $\mathrm{mTa}$ \\
13 & 1,0 & $\mathrm{ENE}$ & - & - & 2 & $\mathrm{mTa}$ \\
14 & 1,6 & $\mathrm{NNE}$ & - & - & 4 & $\mathrm{mTa}$ \\
15 & 1,6 & $\mathrm{SW}$ & 2,4 & 5,83 & 8 & $\mathrm{FPA}$ \\
16 & 1,2 & $\mathrm{E}$ & - & 0,5 & 6 & $\mathrm{mPa}$ \\
17 & 1,1 & $\mathrm{E}$ & - & - & 6 & $\mathrm{mPa}$ \\
18 & 1,9 & $\mathrm{~W}$ & - & - & 4 & $\mathrm{mPa}$ \\
19 & 2,3 & $\mathrm{SW}$ & - & - & 6 & $\mathrm{mPa}$ \\
20 & 2,4 & $\mathrm{E}$ & - & - & 2 & $\mathrm{mPa}$ \\
21 & 1,6 & $\mathrm{E}$ & - & - & 2 & $\mathrm{mPa}$ \\
22 & 1,0 & $\mathrm{E}$ & - & 0,25 & 2 & $\mathrm{mTa}$ \\
23 & 0,6 & $\mathrm{SE}$ & - & - & 2 & $\mathrm{mTa}$ \\
24 & 2,5 & $\mathrm{E}$ & - & - & 4 & $\mathrm{FPA}$ \\
25 & 3,0 & $\mathrm{E}$ & - & - & 4 & $\mathrm{mPa}$ \\
26 & 2,6 & $\mathrm{E}$ & - & - & 4 & $\mathrm{mPa}$ \\
27 & 1,8 & $\mathrm{E}$ & - & - & 2 & $\mathrm{mPa}$ \\
28 & 1,2 & $\mathrm{E}$ & - & - & 6 & $\mathrm{mPa}$ \\
29 & 1,3 & $\mathrm{E}$ & - & - & 4 & $\mathrm{mTa}$ \\
30 & 1,9 & $\mathrm{NE}$ & 13,0 & 53,08 & 4 & $\mathrm{FPA}$ \\
\hline & & & & & \\
\hline
\end{tabular}

*Células com realce correspondem aos dias selecionados para comparar a intensidade das ilhas de calor $\left(\triangle T_{\mathrm{LCZ} X-Y}\right)$ e célula com bordas externas corresponde ao dia selecionado para análise diária. Fonte: (a) INMET; (b) Davis Vantage Pro2; (c) ASOS; (d) Amorim (2017,2020). 
Tabela 2 - Dados meteorológicos de dezembro de 2015 em Presidente Prudente

\begin{tabular}{|c|c|c|c|c|c|c|}
\hline Dia & $\begin{array}{c}\text { Velocidade média } \\
\text { do vento }\left(\mathrm{m} \mathrm{s}^{-1}\right) \\
\text { a }\end{array}$ & $\begin{array}{c}\text { Direção } \\
\text { predominante } \\
\text { do vento }^{a}\end{array}$ & $\begin{array}{l}\text { Precipitação } \\
\text { área urbana } \\
(\mathrm{mm})^{a}\end{array}$ & $\begin{array}{l}\text { Precipitação } \\
\text { área rural } \\
(\mathrm{mm})^{\mathrm{b}}\end{array}$ & $\begin{array}{l}\text { Cobertura } \\
\text { de nuvens } \\
\text { (oktas) }^{c}\end{array}$ & $\begin{array}{c}\text { Sistemas } \\
\text { atmosféricos } \\
d\end{array}$ \\
\hline 1 & 1,2 & $\mathrm{E}$ & 2,0 & 0,51 & 3 & FPA \\
\hline 2 & 1,1 & $E$ & - & - & 3 & $\mathrm{mTa}$ \\
\hline 3 & 0,7 & E & 17,8 & 16 & 4 & I \\
\hline 4 & 0,7 & $\mathrm{E}$ & 5,6 & 24,62 & 4 & I \\
\hline 5 & 0,8 & SW & 0,2 & - & 3 & FPA \\
\hline 6 & 0,7 & W & 7,2 & 18,28 & 5 & FPA \\
\hline 7 & 0,5 & W & - & - & 4 & $\mathrm{mPa}$ \\
\hline 8 & 0,7 & $E$ & 8,2 & 2,03 & 7 & I \\
\hline 9 & 0,9 & NE & 1,6 & 7,87 & 5 & FPA \\
\hline 10 & 1,5 & NW & 11,4 & 13,97 & 3 & FPA \\
\hline 11 & 0,7 & $\mathrm{~N}$ & - & - & 2 & FPA \\
\hline 12 & 0,8 & $E$ & 17,8 & 29,96 & 7 & I \\
\hline 13 & 2,1 & $\mathrm{~N}$ & - & 0,5 & 3 & $\mathrm{mTa}$ \\
\hline 14 & 1,3 & $\mathrm{~N}$ & - & - & 2 & $\mathrm{mTa}$ \\
\hline 15 & 0,7 & $E$ & - & - & 2 & FPA \\
\hline 16 & 0,7 & NE & 1,0 & - & 7 & FPA \\
\hline 17 & 1,3 & $\mathrm{E}$ & - & - & 2 & $\mathrm{mTa}$ \\
\hline 18 & 1,0 & $\mathrm{NE}$ & 3,0 & 22,86 & 4 & $\mathrm{mTa}$ \\
\hline 19 & 0,6 & NE & 7,2 & 10,15 & 3 & FPA \\
\hline 20 & 0,3 & $E$ & 5,0 & 2,02 & 2 & FPA \\
\hline 21 & 0,9 & $\mathrm{E}$ & - & - & 5 & $\mathrm{mPa}$ \\
\hline 22 & 1,4 & $E$ & 1,0 & - & 5 & $\mathrm{mTa}$ \\
\hline 23 & 0,9 & NE & 1,2 & - & 7 & $\mathrm{mTa}$ \\
\hline 24 & 0,8 & $\mathrm{E}$ & - & - & 4 & $\mathrm{mTa}$ \\
\hline 25 & 0,7 & SW & - & - & 4 & $\mathrm{mTa}$ \\
\hline 26 & 0,4 & ENE & 13,6 & 25,65 & 7 & FPA \\
\hline 27 & 0,5 & $\mathrm{NE}$ & - & 26,41 & 2 & $\mathrm{mPa}$ \\
\hline 28 & 1,3 & $\mathrm{~N}$ & 8,2 & 22,1 & 7 & ZCOU \\
\hline 29 & 1,1 & ENE & 65,2 & 54,85 & 7 & ZCOU \\
\hline 30 & 2,0 & $\mathrm{~N}$ & 25,8 & 6,86 & 7 & $\mathrm{FE}$ \\
\hline 31 & 2,0 & W & 0,2 & 0,25 & 5 & $\mathrm{mTa}$ \\
\hline
\end{tabular}

*Células com realce correspondem aos dias selecionados para comparar a intensidade das ilhas de calor $\left(\Delta T_{L C Z} X-Y\right)$ e célula com bordas externas corresponde ao dia selecionado para análise diária. Fonte: (a) INMET; (b) Davis Vantage Pro2; (c) ASOS; (d) Amorim $(2017,2020)$.

Os meses de junho e dezembro de 2015 também correspondem ao período no qual os sensores instalados nas LCZs 3 e B monitoraram a temperatura do ar e umidade relativa do ar. Os dados horários foram registrados por uma estação meteorológica Davis Vantage Pro2 na LCZ 3 e um data logger da marca HOBO (U23-002) com abrigo de radiação solar RS3 na LCZ B (Quadro 1).

A partir dos dados registrados nas LCZs, calculou-se a intensidade da

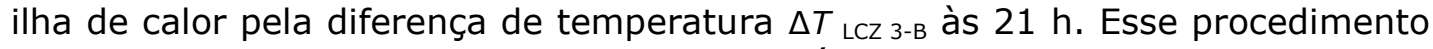
auxiliou identificar os dias cujas diferenças térmicas entre as LCZs foram mais elevadas: 11 de junho e 17 de dezembro de 2015, os quais foram selecionados para a modelagem futura com o ENVI-met. 
Quadro 1 - Equipamentos utilizados nas medições

\begin{tabular}{|l|l|}
\hline Equipamento & \multicolumn{1}{|c|}{ Variável registrada } \\
\hline Temperatura do ar \\
Acurácia: $\pm 0,21^{\circ} \mathrm{C}$ de $0{ }^{\circ}$ a $50^{\circ} \mathrm{C}$ \\
Resolução: $0,02^{\circ} \mathrm{C}$ \\
Umidade relativa do ar \\
Acurácia: $\pm 2,5 \%$ de $10 \%$ a $90 \%$ \\
Resolução: $0,05 \%$
\end{tabular}

Fonte: Davis Instruments (2019) e HOBO Data Loggers (2017)

\section{RESULTADOS E DISCUSSÃO}

\subsection{PROPRIEDADES DE COBERTURA DA SUPERFÍCIE E MATERIAIS CONSTRUTIVOS}

A abordagem de classificação adotada nessa pesquisa gerou mapas de cobertura da terra para as LCZs em Presidente Prudente com os materiais de construção predominantes (Fig. 6). Os valores percentuais dessas propriedades estão descritos na Tabela 3. 
Zonas Climáticas Locais*

LCZ 3 - Compacta de baixa elevação

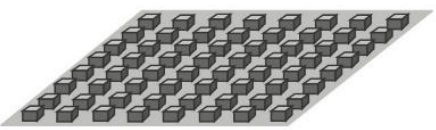

LCZ B - Vegetação arbórea esparsa

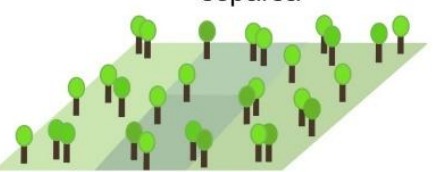

Latitude: 464159

Longitude: 7552443

Altitude média: 396 m

FSE: $0.4 \%$

FSP: $99.5 \%$

\section{Informações**}
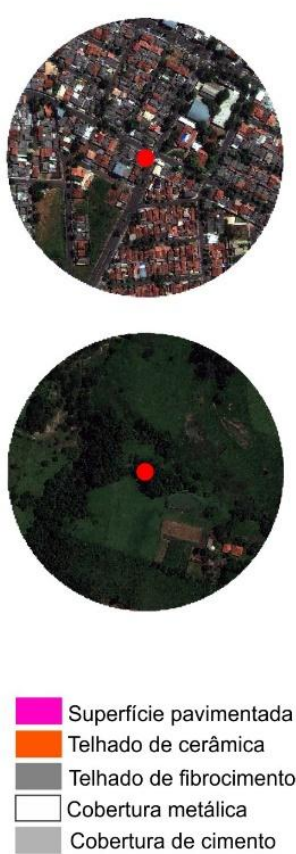

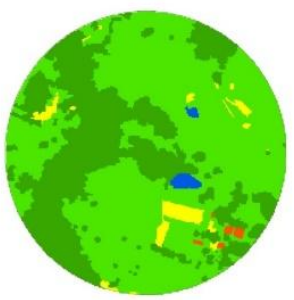

\section{Classificação}

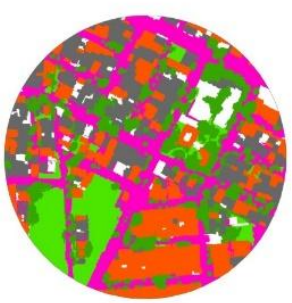

Solo exposto

Árvore

Graminea

Água
Cobertura de cimento

FSE: fração da superfície com edificios

FSI: fração da superfície impermeável

FSP: fração da superfície permeável

Figura 6 - Mapas de cobertura da terra e materiais de construção predominantes nas LCZs em Presidente Prudente. Fonte: Adaptado de Cardoso et al. (2018).

Tabela 3 - Porcentagem das propriedades de cobertura da superfície e materiais construtivos nas LCZs em Presidente Prudente ${ }^{5}$

\begin{tabular}{llcc}
\hline Cobertura da superfície & \multicolumn{1}{c}{ Propriedades } & LCZ 3 (\%) & LCZ B (\%) \\
\hline \multirow{2}{*}{ Edifícios } & Telhado de cerâmica & 21,5 & 0,4 \\
& Telhado de fibrocimento & 20,8 & - \\
\multirow{2}{*}{ Superfície impermeável } & Cobertura metálica & 5,2 & - \\
& Pavimento & 24,1 & - \\
& Solo exposto & - & 2,9 \\
Superfície permeável & Árvore & 17,8 & 33,6 \\
& Gramínea & 10,6 & 62,3 \\
& Água & - & 0,7 \\
\hline
\end{tabular}

Fonte: Adaptado de Cardoso et al. (2018)

Com base nas porcentagens de propriedades de cobertura da superfície e materiais de construção extraídos dos mapas da Figura 6, foram calculadas as frações de superfícies com edifícios, superfícies impermeáveis e permeáveis para cada LCZ (Tabela 4).

\footnotetext{
${ }^{5} \mathrm{O}$ percentual de superfície permeável com vegetação arbórea na LCZ 3 pode estar superestimado, tendo em vista que a informação foi obtida a partir do mapeamento da copa das árvores.
} 
Tabela 4 - Valores das propriedades de cobertura da superfíce das LCZs em Presidente Prudente em comparação com os intervalos estabelecidos por Stewart e Oke (2012)

\begin{tabular}{ccclc}
\hline \multirow{2}{*}{ Propriedades } & \multicolumn{2}{c}{ LCZ 3 } & \multicolumn{2}{c}{ LCZ B } \\
\cline { 2 - 5 } & $\begin{array}{c}\text { Presidente } \\
\text { Prudente }\end{array}$ & $\begin{array}{c}\text { Stewart e Oke } \\
(2012)\end{array}$ & $\begin{array}{l}\text { Presidente } \\
\text { Prudente }\end{array}$ & $\begin{array}{l}\text { Stewart e Oke } \\
(2012)\end{array}$ \\
\hline $\begin{array}{c}\text { Fração da superfície } \\
\text { edificada (\%) }\end{array}$ & 47,6 & $40-70$ & 0,4 & $<10$ \\
$\begin{array}{c}\text { Fração da superfície } \\
\text { impermeável (\%) }\end{array}$ & 24,1 & $20-50$ & - & $<10$ \\
$\begin{array}{c}\text { Fração da superfície } \\
\text { permeável (\%) }\end{array}$ & 28,3 & $<30$ & 99,5 & $>90$ \\
\hline
\end{tabular}

Fonte: Adaptado de Cardoso et al. (2018)

\subsection{ESTIMATIVA DA GEOMETRIA}

A superfície urbana é composta por uma grande diversidade de materiais naturais e fabricados, com refletividades e emissividades distintas, dispostos em uma estrutura 3D. O resultado é uma composição multifacetada, com superfícies de inclinações e orientações únicas, que podem emitir ou refletir umas às outras ou bloquear essas trocas, gerando diferentes balanços de radiação (OKE et al., 2017).

As diferentes configurações urbanas influenciam nas condições térmicas do ambiente, fato demonstrado por Oke (1988) através das relações entre a geometria e o microclima dos cânions urbanos. De acordo com o autor, a geometria afeta a dispersão de poluentes na cidade, uma vez que a rugosidade da superfície influencia a turbulência mecânica, a forma do perfil vertical do vento e a profundidade da camada de mistura urbana. Além disso, a circulação e turbulência associadas aos cânions também produzem efeitos de microescala entre os edifícios e logo acima deles.

Com relação ao aquecimento urbano, Oke $(1981,1988)$ destaca que as formas compactas na cidade promovem o calor devido ao aumento da absorção de ondas curtas, ao aprisionamento dentro de cânions, à diminuição da perda de calor por turbulência devido à estagnação em cânions profundos e à diminuição da perda de radiação de ondas longas dos cânions devido à redução do fator de visão do céu. Somado a isso,

Pode-se esperar que densidades maiores sejam acompanhadas por maiores quantidades de cobertura impermeável, materiais com maior admissão térmica e maior densidade de fluxo de calor antropogênico. Por sua vez, esses recursos favorecem o calor sensível, e não o latente, o armazenamento de calor, e não a troca de calor e a disponibilidade extra de energia (OKE, 1988, p. 109, tradução nossa).

Um dos parâmetros mais utilizados para caracterizar a geometria urbana é a razão do aspecto do cânion $H / W$, cujos valores podem variar de $<0,1$ em LCZs referentes aos arranjos abertos de cobertura da terra; $>1$ com vegetação 
arbórea densa; 0,3 a 1,25 em áreas construídas espaçadas; e 0,75 a >2 em áreas construídas compactas (STEWART; OKE, 2012).

Em Presidente Prudente, a LCZ 3 apresentou $H / W=0,3$, valor pouco abaixo da faixa proposta por Stewart e Oke (2012) para áreas densamente construídas. Isso pode ser relacionado ao predomínio de edifícios baixos, com altura média de $3 \mathrm{~m}$, enquanto o espaçamento médio entre as vias foi de $11 \mathrm{~m}$.

Por outro lado, na LCZ B foi estimada $H=10 \mathrm{~m}, W=16,5$ e razão do aspecto $H / W=0,6$, valor dentro da faixa esperada para a classe de vegetação arbórea esparsa $(0,25-0,75)$.

\subsection{FICHAS TÉCNICAS}

O layout, as ilustrações e as propriedades das LCZs foram baseadas nos materiais propostos por Stewart $(2011,2018)$ e Stewart e Oke (2012), sendo que os dados das propriedades representativas das LCZs em Presidente Prudente estão escritos em vermelho. As figuras ilustrativas da vista oblíqua foram obtidas no Google Earth Pro, com altitude média (eye altitude) de 800 m, enquanto as da vista lateral foram fotografadas durante o levantamento de dados nas áreas de estudo.

A LCZ 3, localizada na área oeste da cidade, compreende funções residenciais (habitação de unidade única) e comerciais (pequenas lojas). Apresenta fluxo de tráfego moderado a alto e prédios de 1 a 2 andares pouco espaçados, dispostos em ruas estreitas. Aproximadamente $48 \%$ da sua superfície é coberta por edifícios, e os materiais construtivos incluem concreto, telhas de cerâmica/fibrocimento e telhado metálico. Cerca de $24 \%$ da superfície é pavimentada, com algumas árvores esparsas nas quadras (Fig. 7).

A LCZ B corresponde a uma área com cobertura vegetal remanescente no entorno rural próximo a leste da malha urbana, caracterizada por paisagem arborizada de árvores perenes, dispersas em superfície com vegetação rasteira. Existem poucas estradas com baixo fluxo de tráfego e menos de $0,5 \%$ da superfície está coberta com construções (Fig. 8). 


\section{DEFINIÇÃO}

Forma: Edifícios baixos e pequenos, contíguos ou pouco espaçados ao longo de ruas estreias. Materiais de construção pesados (pedra, cimento, tijolo) e predomínio de telhados de fibrocimento e cerâmica. Cobertura da terra pavimentada, com poucas ou nenhuma árvore. Fluxo de tráfego baixo a médio. Função: Residencial (habitação de unidade única) e comercial (pequenas lojas). Localização: Oeste da cidade. Correspondência: UCZ3 (Oke, 2004); Dc3 (Ellefsen, 1990/91).

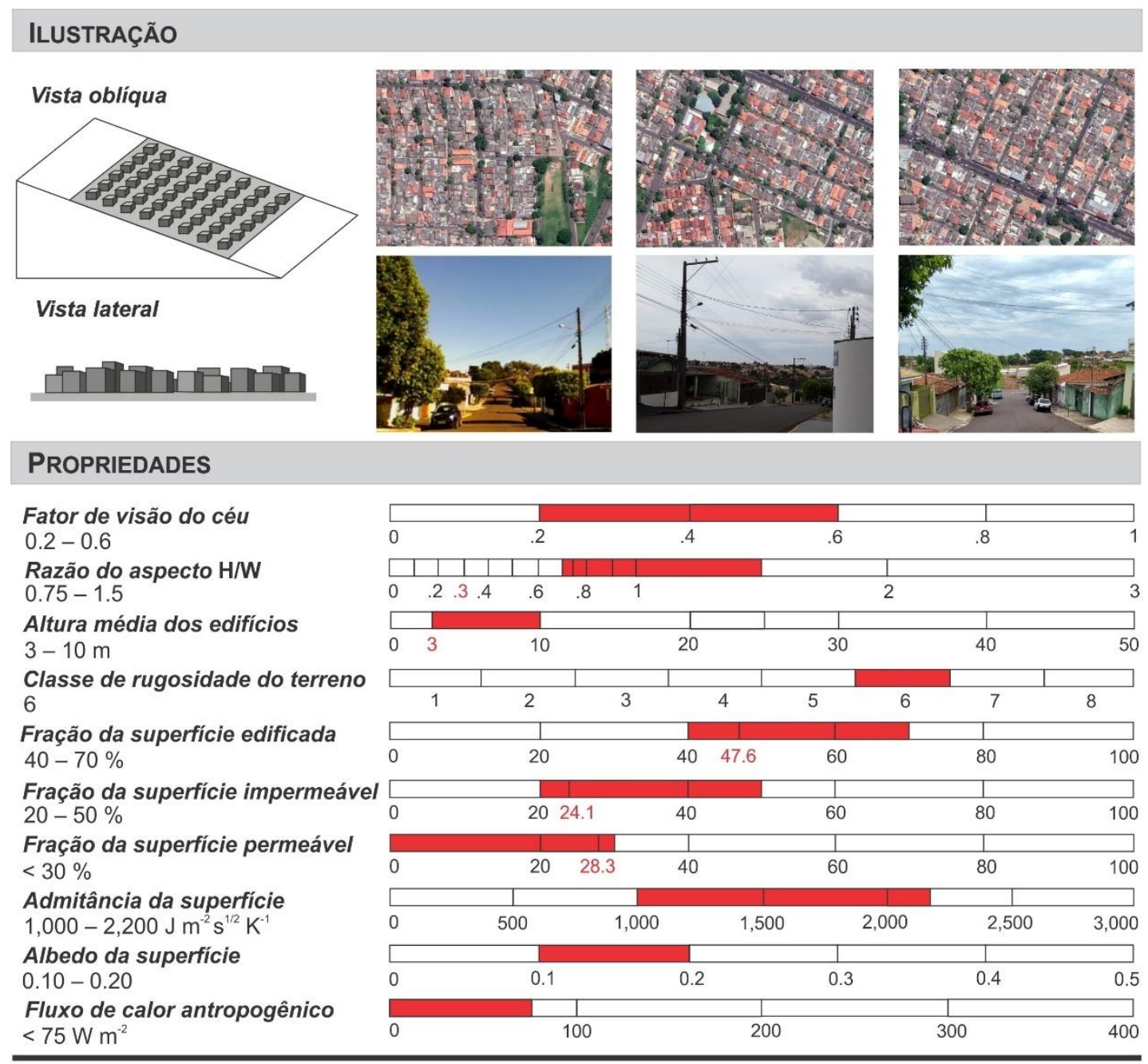

*Valores calculados na área representativa da LCZ (raio de 200 m)

Figura 7 - LCZ 3: Compacta de baixa elevação. Fonte: Elaborado pela autora. Adaptado de Stewart $(2011,2018)$ e Stewart e Oke (2012) 


\section{DEFINIÇÃO}

Forma: Paisagem levemente arborizada. Árvores dispersas em terreno permeável (vegetação rasteira). Pouca presença de vias (sem cobertura asfáltica) e edifícios espaçados. Baixo ou nenhum fluxo de tráfego. Função: Vegetação arbórea remanescente natural ou replantio, cultivos. Localização: Área rural a leste da cidade.

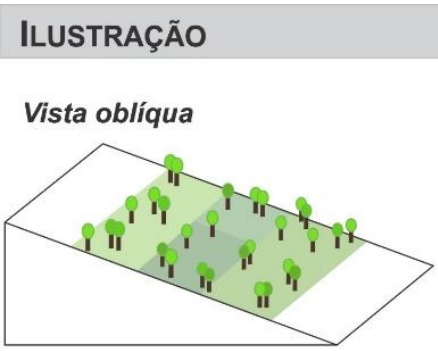

Vista lateral

\section{init iri in int}
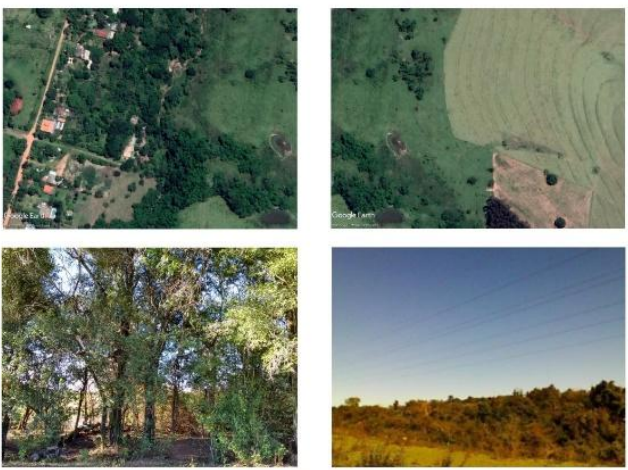

\section{PROPRIEDADES}

Fator de visão do céu

$0.5-0.8$

Razão do aspecto H/W

$0.25-0.75$

Altura média das árvores

3-15 m

Classe de rugosidade do terreno 5-6

Fração da superfície edificada $<10 \%$

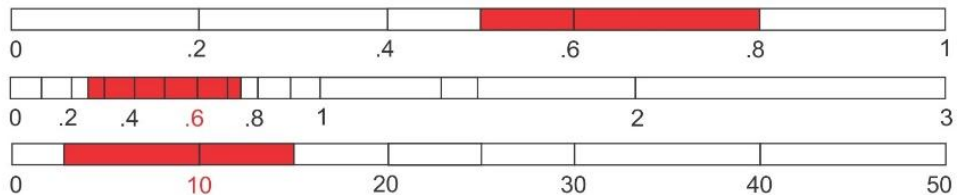

\begin{tabular}{llllll}
\hline 10 & 20 & 30 & 40 & 50
\end{tabular}

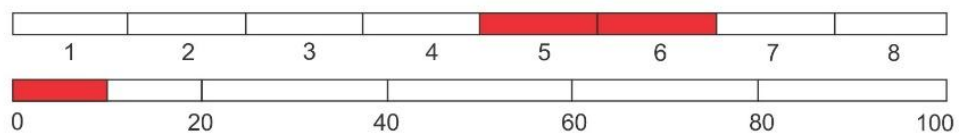

Fração da superfície impermeáve $<10 \%$

Fração da superfície permeável $>90 \%$

Admitância da superfície $1,000-1,800 \mathrm{~J} \mathrm{~m}^{-2} \mathrm{~s}^{1 / 2} \mathrm{~K}^{-1}$

Albedo da superfície

$0.15-0.25$

Fluxo de calor antropogênico $0 \mathrm{~W} \mathrm{~m}^{-2}$

\begin{tabular}{|l|l|l|l|l|l|l|r|}
\hline & & & & & & \\
\hline \\
\hline
\end{tabular}

*Valores calculados na área representativa da LCZ (raio de $200 \mathrm{~m}$ )

Figura 8 - LCZ B: Vegetação arbórea esparsa. Fonte: Elaborado pela autora. Adaptado de Stewart $(2011,2018)$ e Stewart e Oke (2012)

\subsection{CARACTERÍSTICAS DAS VARIÁVEIS CLIMÁTICAS}

\subsubsection{JUNHO DE 2015}

O mês de junho apresentou temperatura média do ar de $21,1^{\circ} \mathrm{C}$, máxima de $30,6^{\circ} \mathrm{C}$ e mínima de $11,6^{\circ} \mathrm{C}$. A média diária de radiação solar global (RSG) ${ }^{6}$

${ }^{6}$ Em decorrência de um problema técnico no registro da RSG na estação meteorológica Presidente Prudente-A707, foram utilizados os dados de RSG da estação de Rancharia-SP (A718, Código OMM: 86864), a 60 km de distância de Presidente Prudente. 
foi de $153,6 \mathrm{~W} \mathrm{~m}^{-2}$, a umidade relativa do ar média foi de $66 \%$ e o total de precipitação foi de $21,2 \mathrm{~mm}$. Os ventos apresentaram velocidade média de 1,4 $\mathrm{m} \mathrm{s}^{-1}$, com direções predominantes de ESE, E, ENE e NE, respectivamente. As situações de calmaria totalizaram $23,8 \%$, enquanto ventos de até $2,1 \mathrm{~m} \mathrm{~s}^{-1}$ ocorreram em $52,9 \%$ do tempo e em apenas $4,7 \%$ foram classificados entre 3,6 e $5,7 \mathrm{~m} \mathrm{~s}^{-1}$ (Fig. 9a).

No dia 11 de junho, a temperatura máxima atingiu $29,9^{\circ} \mathrm{C}$, com média de $24,5^{\circ} \mathrm{C}$, mínima de $19,7^{\circ} \mathrm{C}$, e média da RSG de $183,3 \mathrm{~W} \mathrm{~m}^{-2}$. A umidade relativa do ar média foi de $56 \%$, com mínima de $37 \%$ e máxima de $72 \%$. Os ventos sopraram do quadrante norte, predominantemente, com velocidade média de $1,2 \mathrm{~m} \mathrm{~s}^{-1}$ e máxima registrada de $3,8 \mathrm{~m} \mathrm{~s}^{-1}$. Durante $50 \%$ do tempo ocorreu situação de calmaria, em $20,8 \%$ as velocidades variaram entre 2,1 e $3,6 \mathrm{~m} \mathrm{~s}^{-1}$, e em $4,2 \%$ os ventos foram de 3,6 e $5,7 \mathrm{~m} \mathrm{~s}^{-1}$ (Fig. 9b).

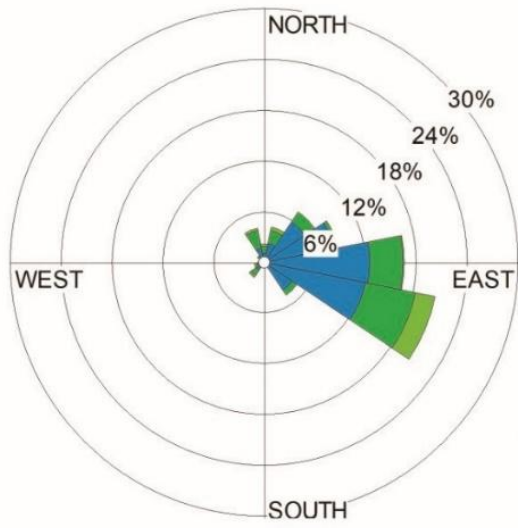

(a) junho 2015

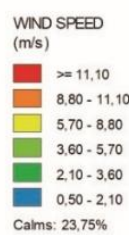

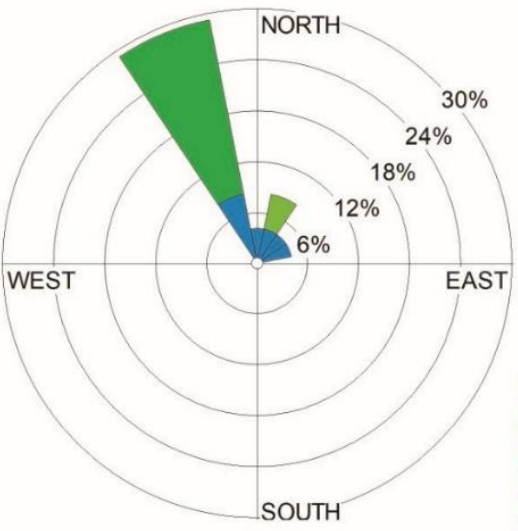

(b) 11 junho 2015

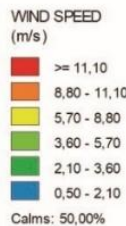

Figura 9 - Frequência da direção e velocidade dos ventos em junho de 2015

Observa-se na Figura 10a que as variações de temperatura do ar nas LCZs acompanharam a curva de radiação solar, com o aumento dos valores no nascer do sol, temperaturas mais elevadas no período de maior incidência de raios solares e diminuição após o pôr do sol.

Com relação à umidade relativa (Fig. 10b), por ser dependente da temperatura do ar, apresentou estreita relação inversa com o padrão das curvas de aquecimento e resfriamento. Os percentuais mais elevados em ambas LCZs ocorreram no período noturno, com valores mínimos no período de maior aquecimento diurno. De forma geral, a umidade mais baixa na LCZ 3 durante o dia analisado pode ser relacionada às menores taxas de evapotranspiração, devido principalmente à menor fração da cobertura vegetal na área residencial urbana.

A LCZ 3 registrou temperatura máxima acima de $30^{\circ} \mathrm{C}$ e mínima de $18,9^{\circ} \mathrm{C}$, e valores de umidade relativa entre $33 \%$ e $78 \%$. A LCZ B registrou temperatura máxima de $29,4^{\circ} \mathrm{C}$ e mínima de $14,6^{\circ} \mathrm{C}$, com umidade relativa máxima de aproximadamente $97 \%$. No que diz respeito à intensidade da ilha de calor, $\Delta T_{\mathrm{LCZ}}$ 3-B variou de $0,6^{\circ} \mathrm{C}$ a $6,8^{\circ} \mathrm{C}$, enquanto a diferença de umidade entre as LCZs ( $\triangle U R$ LCZ 3-B) variou de $-8,3 \%$ a $-35,3 \%$.

Nesse episódio representativo do inverno, notou-se que as temperaturas nas LCZs apresentaram um padrão similar ao aquecimento e resfriamento das 
áreas urbanas e rurais descritas por Oke et al. (2017) em condições de tempo estáveis. Apesar de os valores máximos de temperatura do ar serem semelhantes nesses ambientes, o mínimo é menor na área rural, o que resultou na maior amplitude térmica verificada na LCZ B.

Próximo ao nascer do sol, a área rural estava com temperaturas mais frias, mas em seguida os valores aumentaram rapidamente. Embora o sensor tenha sido instalado abaixo da copa das árvores, muitas perdem folhas nesse período com menor pluviosidade, o que deixa a superfície natural mais exposta ao sol e seus efeitos no aquecimento em comparação com a superfície urbana.

11 Junho 2015
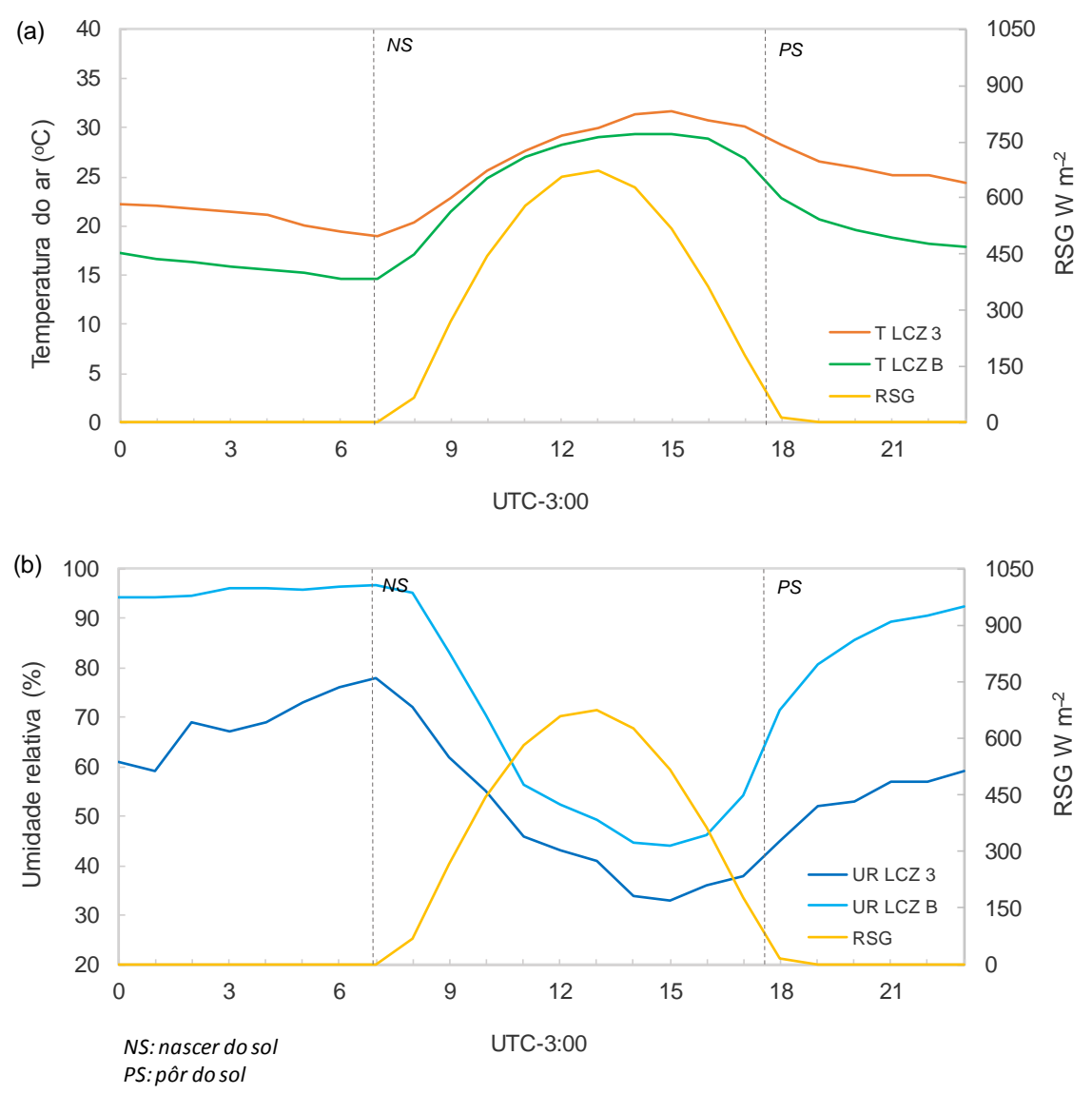

Figura 10 - Temperatura do ar, umidade relativa e RSG nas LCZs em 11 de junho de 2015

O aquecimento da camada do dossel urbano é mais lento no início do dia, pois os cânions estão geralmente sombreados e as temperaturas da superfície aquecem menos rapidamente devido à alta admitância térmica dos materiais construtivos.

No final da tarde e no início da noite, as temperaturas começam a diminuir em ambos os ambientes, sendo que as taxas de resfriamento do rural podem atingir $3^{\circ} \mathrm{C} \mathrm{h}^{-1}$, enquanto as taxas urbanas são tipicamente inferiores a $1^{\circ} \mathrm{C} \mathrm{h}^{-1}$. Essa taxa na área rural pode ser relacionada ao maior fator de visão do 
céu e à menor admitância térmica dos solos secos, enquanto na área urbana há emissões de calor antropogênico, o horizonte é mais restrito e o calor armazenado é liberado lentamente (OKE et al., 2017).

Essa sequência diária se repete após o amanhecer e constitui a essência do efeito das ilhas de calor na camada do dossel, fenômeno noturno que se origina porque as áreas urbanas não conseguem esfriar tão rapidamente quanto o ambiente rural. Como consequência, é impulsionado por diferenças nas taxas de aquecimento e resfriamento urbano, que criam a variação diurna das ilhas de calor (OKE et al., 2017).

\subsubsection{DEZEMBRO DE 2015}

O mês de dezembro apresentou temperatura média do ar de $25,9^{\circ} \mathrm{C}$, máxima de $35,8^{\circ} \mathrm{C}$ e mínima de $18,2^{\circ} \mathrm{C}$. A umidade relativa do ar foi em média $75 \%$, a precipitação totalizou 203,2 mm e a média diária de RSG atingiu 217,2 $\mathrm{W} \mathrm{m}^{-2}$. A velocidade média dos ventos foi de $1 \mathrm{~m} \mathrm{~s}^{-1}$, com direções predominantes de NNE, E, ESE, NE, N e NW, respectivamente. Durante $45 \%$ do tempo houve calmaria e em $42 \%$ as velocidades variaram entre 0,5 e $2,1 \mathrm{~m} \mathrm{~s}^{-1}$ (Fig. 11a).

No dia 17 de dezembro a temperatura máxima foi de $33,9^{\circ} \mathrm{C}$, com média de $27,2^{\circ} \mathrm{C}$ e mínima de $21,9^{\circ} \mathrm{C}$. A RSG média foi de $335,1 \mathrm{~W} \mathrm{~m}^{-2}$, e a umidade relativa do ar média foi de $64 \%$, com mínima de $44 \%$ e máxima de $85 \%$. Por sua vez, a velocidade média do vento foi de $1,3 \mathrm{~m} \mathrm{~s}^{-1}$ e a máxima atingiu $2,8 \mathrm{~m}$ $\mathrm{s}^{-1}$. Os ventos sopraram da direção $E$ com velocidades entre 0,5 e $2,1 \mathrm{~m} \mathrm{~s}^{-1}$ durante $25 \%$ do tempo, enquanto das direções ENE, NE e NNE totalizaram 39\% nessa mesma classe de velocidade (Fig. 11b).

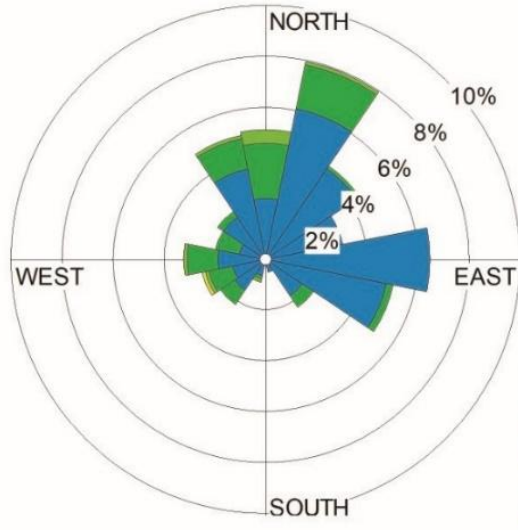

(a) dezembro 2015

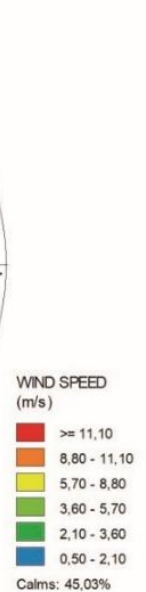

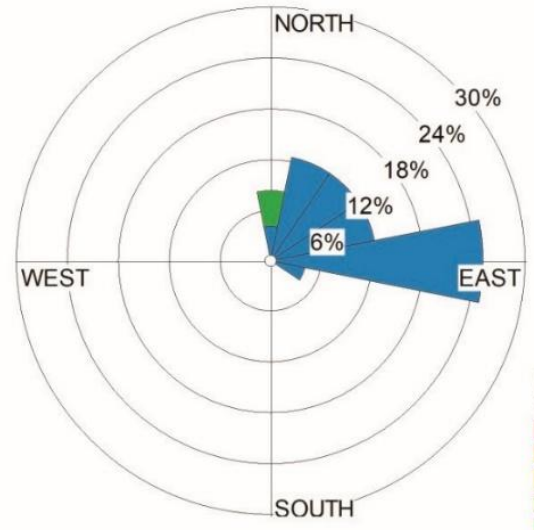

(b) 17 dezembro 2015

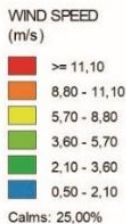

Figura 11 - Frequência da direção e velocidade dos ventos em dezembro de 2015

As variações térmicas nas LCZs no dia 17 de dezembro (Fig. 12a) também acompanharam os valores de RSG incidente, com temperaturas máximas acima de $34^{\circ} \mathrm{C}$ na $\mathrm{LCZ} 3$ e mínima de $21,6^{\circ} \mathrm{C}$ na $\mathrm{LCZ} B$. Diferente do ocorrido em 11 de junho, a LCZ B registrou temperaturas um pouco mais próximas das verificadas na área urbana, o que pode estar relacionado à maior admitância térmica dos solos úmidos, em decorrência do aumento no total pluviométrico. 
17 Dezembro 2015
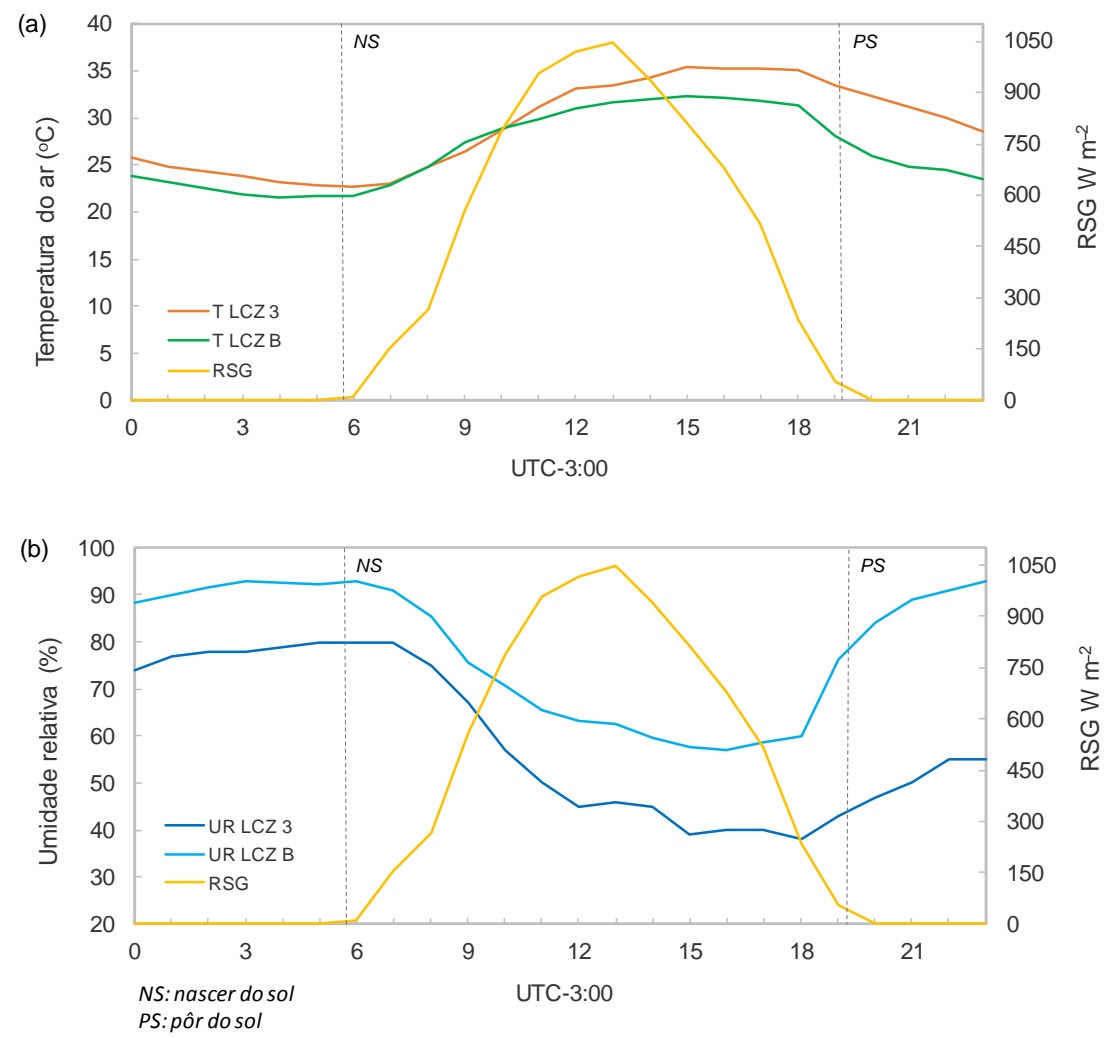

Figura 12 - Temperatura do ar, umidade relativa e RSG nas LCZs em 17 de dezembro de 2015

As temperaturas das LCZs se aproximaram no período da manhã, de modo que se observou $\Delta T$ LCZ з-B de $-1,0^{\circ} \mathrm{C}$, ou seja, temperatura mais elevada na LCZ B; caracterizando uma ilha de frescor. As diferenças de umidade relativa também foram menores nesse período e aumentaram durante a tarde, com $\Delta U R$ LCZ 3-в máxima de aproximadamente $-40 \%$ no período noturno (Fig. 12b).

Nesse episódio representativo do verão, as diferenças térmicas foram relativamente menores do que as verificadas no inverno. No entanto, observouse um padrão similar de aquecimento e resfriamento das áreas urbana e rural, sobretudo a capacidade da LCZ B em se resfriar com maior rapidez no final da tarde e início da noite, o que resultou em intensidades $\Delta T$ LCZ 3-в de até $6,4^{\circ} \mathrm{C}$.

\section{CONCLUSÕES}

As ilhas de calor em cidades de clima tropical têm implicações negativas, que envolvem desde a intensificação do desconforto térmico para a população, até o aumento da demanda de energia com o uso de ar condicionado. Logo, investigar as interações entre superfície e atmosfera para compreender os mecanismos associados a esse fenômeno, assim como a descrição e modelagem adequadas (OKE et al. 2017), são medidas necessárias para minimizar efeitos indesejados no clima das cidades. 
A partir da proposta de Stewart e Oke (2012), esse estudo investigou propriedades da superfície que influenciam o campo térmico na camada do dossel, como materiais construtivos, cobertura da terra e geometria. Associadas às variáveis climáticas representativas da área de estudo, o levantamento contribuiu para a caracterização de LCZs em Presidente Prudente e servirá como base de dados de entrada para as simulações com o modelo ENVI-met.

A medição ou estimativa das propriedades da superfície confirmaram a correspondência das LCZs 3 e B com os dados da proposta dos autores. No entanto, verificou-se a necessidade de investigar o fator de visão do céu $\left(\psi_{s k y}\right)$ em estudos futuros. Definido como a fração do céu visível do nível da superfície,

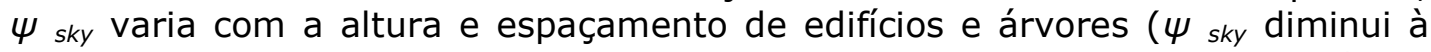
medida que $H / W$ aumenta), e afeta o aquecimento/resfriamento por radiação da superfície (STEWART; OKE, 2012; OKE et al., 2017).

Com relação às variáveis climáticas, os resultados demonstraram que os contrastes térmicos entre LCZs com diferentes geometrias e coberturas da terra podem exceder $6^{\circ} \mathrm{C}$. A intensidade máxima das ilhas de calor $\Delta T$ LCZ 3-в foi de $6,8^{\circ} \mathrm{C}$ no período mais seco (inverno), diminuindo para $6,4^{\circ} \mathrm{C}$ no período tipicamente mais chuvoso (verão).

A ênfase para um episódio representativo do inverno e outro do verão deve-se ao fato desse estudo ser parte de uma pesquisa mais ampla, que envolveu a definição das condições ideais para a modelagem numérica. No entanto, destaca-se a importância das análises horárias por vários dias ou

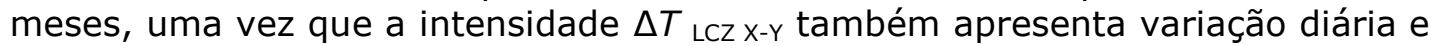
sazonal, em diferentes condições atmosféricas.

\section{AGRADECIMENTOS}

Ao Conselho Nacional de Desenvolvimento Científico e Tecnológico CNPq (processo: 141424/2017-6), à Coordenação de Aperfeiçoamento de Pessoal de Nível Superior - CAPES (processo: PDSE - 88881.188727/2018-01) e à Fundação de Amparo à Pesquisa do Estado de São Paulo - FAPESP (processo: 2017/03514-6) pelo apoio financeiro. Ao programa CAPES/COFECUB (processo: 88881.191765/2018-01) pelo financiamento do projeto intitulado CiCIAMEn: Cities, Climate And vegetation: Modeling and Environmental public policies.

\section{REFERÊNCIAS}

AMORIM, M. C. C. T. Teoria e método para o estudo das ilhas de calor em cidades tropicais de pequeno e médio porte. 2017. Tese (Livre Docência) Faculdade de Ciências e Tecnologia, Universidade Estadual Paulista, Presidente Prudente, 2017.

AMORIM, M. C. C. T. Ilhas de calor em cidades tropicais de médio e pequeno porte: teoria e prática. Curitiba: Appris, 2020. v. 1. 161p.

CARDOSO, R. S.; AMORIM, M. C. C. T. Análise do clima urbano a partir da segregação socioespacial e socioambiental em Presidente Prudente-SP, Brasil. Geosaberes, 6, p. 122-136, 2015.

CARDOSO, R. S.; AMORIM, M. C. C. T. Urban heat island analysis using the 'local climate zone' scheme in Presidente Prudente, Brazil. Investigaciones 
Geográficas, 69, p. 107-118, $2018 . \quad$ DOI: https://doi.org/10.14198/INGEO2018.69.07

CARDOSO, R. S.; AMORIM, M. C. C. T.; LIU, D.; MONTENEGRO, A. Using highresolution satellite imagery to characterize local climate zones in Presidente Prudente, Brazil. In: 10th International Conference on Urban Climate \& 14th Symposium on the Urban Environment, August 6-10, New York City, USA, 2018.

DAVIS INSTRUMENTS. Vantage Pro2 Console Manual. 2019. Disponível em: https://www.davisinstruments.com/product_documents/weather/manuals/0739 5-234_IM_06312.pdf. Acesso em: mar. 2020.

DUBREUIL, V., FANTE, K. P., PLANCHON, O., SANT'ANNA NETO, J. L. Climate change evidence in Brazil from Koppen's climate annual types frequency. International Journal of Climatology, 39, p. 1446-1456, 2019. DOI: https://doi.org/10.1002/joc.5893

ELLEFSEN, R. Mapping and measuring buildings in the urban canopy boundary layer in ten US cities. Energy and Buildings, 16, p. 1025-1049, 1990/91. DOI: https://doi.org/10.1016/0378-7788(91)90097-M

HESPANHOL, R. A. M. Espaço Rural. In: João Osvaldo Rodrigues Nunes; Isabel Cristina Moroz-Caccia Gouveia; José Mariano Caccia Gouveia. (Org.). Atlas Ambiental Escolar de Presidente Prudente. 1ed. Presidente Prudente: Faculdade de Ciências e Tecnologia, Unesp, 2017.

HOBO DATA LOGgerS. HOBO ${ }^{\circledR}$ Pro v2 (U23-00x) Manual. 2017. Disponível em: https://www.hobodataloggers.com.au/hobo-pro-v2-u23-002-external-tempera turerh-data-logger. Acesso em: mar. 2020.

INSTITUTO BRASILEIRO DE GEOGRAFIA E ESTATÍSTICA. IBGE. População estimada [2019]. Disponível em: https://cidades.ibge.gov.br/brasil/sp/ presidente-prudente/panorama. Acesso em: 12 out. 2019.

NEUFERT, E. Arte de projetar em arquitetura. 18ed. São Paulo: Gustavo Gili, 2013.

NUNES, J. O. R. Caracterização dos aspectos ambientais da Região Administrativa de Presidente Prudente. In: WHITACKER, A. M.; MELAZZO, E. S. (coord.) Conjuntura Prudente 2011. Presidente Prudente, FCT/UNESP, 2011.

OKE, T. R. Canyon geometry and the nocturnal urban heat island: comparison of scale model and field observations. Journal of Climatology, 1, p. 237-254, 1981. DOI: https://doi.org/10.1002/joc.3370010304

OKE, T. R. Boundary Layer Climates. London: Methuen \& Co. 2nd edn. 1987, 435p.

OKE, T. R. Street Design and Urban Canopy Layer Climate. Energy and Buildings, 11, p. 103-113, 1988. DOI: https://doi.org/10.1016/03787788(88)90026-6

$\mathrm{OKE}, \mathrm{T}$. R. Initial guidance to obtain representative meteorological observations at urban sites. IOM Rep. 81, WMO/TD-No. 1250, 47 pp., 2004. Disponível em: https://www.researchgate.net/publication/265347633_Initial_guidance_to_obtai n_representative_meteorological_observations_at_urban_sites. 
OKE, T. R.; MILLS, G. ; CHRISTEN, A. ; VOOGT, J. A. Urban Climates. Cambridge: Cambridge University Press, 2017. DOI: https://doi.org/10.1017/97811390164 76

PRESIDENTE PRUDENTE. Lei complementar no 234, de 27 de dezembro de 2018. Dispõe sobre a Lei de Normas para Edificações do Município, e dá outras providências. Presidente Prudente: Câmara Municipal, 2018. Disponível em: http://www.presidenteprudente.sp.gov.br/site/leis_decretos_detalhe.xhtml?t=3 $\& a=2018 \& n=234 \& c=$. Acesso em: jan. 2019.

SILVA, M. C.; OLIVEIRA, T. A.; VIANA, Y. C. G.; FERREIRA, C. C. M. Campos térmicos urbanos: estudo de caso na zona sul da cidade de Juiz de Fora-MG, a partir de um modelo geoespacial. Revista de Geografia, 8, p. 65-88, 2018. DOI: https://doi.org/10.34019/2236-837X.2018.v8.26000

STEWART, I. D. Landscape representation and urban-rural dichotomy in empirical urban heat island literature, 1950-2006. Acta Climatologica et Chorologica, 40, p. 111-121, 2007.

STEWART, I. D. Redefining the urban heat island. 2011. Thesis (Doctor of Philosophy). The Faculty of Graduate Studies, The University of British Columbia, Vancouver, 2011.

STEWART, I. D. Developing a field guide to identify 'local climate zones' in cities. In: 10th International Conference on Urban Climate \& 14th Symposium on the Urban Environment, August 6-10, New York City, USA, 2018.

STEWART, I. D.; OKE, T. R. Local climate zones for urban temperature studies. Bulletin of the American Meteorological Society, 93 (12), p. 1879-1900, 2012. DOI: https://doi.org/10.1175/BAMS-D-11-00019.1 